\title{
What next for education in evidence-based healthcare? A call for submissions
}

\section{David Nunan $(1),{ }^{1}$ Rod Jackson, ${ }^{2}$ Carl Heneghan (i) ${ }^{1}$}

10.1136/bmjebm-2019-111301

\author{
${ }^{1}$ Primary Care Health \\ Sciences, University of \\ Oxford, Oxford, UK \\ ${ }^{2}$ Epidemiology and \\ Biostatistics, University of \\ Auckland, Auckland, New \\ Zealand
}

Correspondence to: Dr David Nunan, Primary Care Health Sciences, University of Oxford, Oxford OX1 2JD, UK; david.nunan@phc.ox.ac.uk

D Check for updates

๑ Author(s) (or their employer(s)) 2020. No commercial re-use. See rights and permissions. Published by BMJ.

To cite: Nunan D, Jackson R, Heneghan C. BMJ

Evidence-Based Medicine 2020;25:41-43.
The medical curriculum should reflect this importance of changing information for today's practitioner-the necessary skills must be taught and assessed with the same rigour as the physical examination. ${ }^{1}$

\section{Shaping the who, what, when and how} for the teaching of Evidence-Based Health Care in the next 20 years

Nearly three decades ago, Gordan Guyatt, David Sackett and colleagues published 'Evidence-Based Medicine: A New Approach to Teaching the Practice of Medicine' and introduced the term synonymous with medical practice as we know it today. ${ }^{2}$ A 'paradigm shift' in medical practice and teaching took place-the explicit use of medical literature (alongside traditional skills) to guide medical practice and the demand for formal training on the effective use of evidence in day-to-day patient care.

The words 'teach', 'teacher/s', 'teaching', 'educate', 'educator/s', 'educating' and 'education' are used 53 times in this seminal article; 'practice' 46 times; over half of the article describes effective EBM teaching and implementation in medical training. The emphasis was on teaching 'new skills' that were 'not traditionally part of medical training' and further evaluations of the EBM approach.

Today, we announce plans for a stream of BMJ EBM content to revisit efforts to teach the skills of EBM and ask you to join us. A key aim is to discuss, debate and demonstrate effective teaching. Where necessary, we want to challenge current practice and consider the next paradigm shift in teaching and practice. And where possible, we want to challenge with evidence.

\section{A brief history of teaching EBM}

Systematic use of research evidence to inform decisions in healthcare practice is a relatively new idea. Frustrated by uncertainty at the bedside, Alvin Feinsten introduced clinical epidemiology in the late 1960s. This frustration, shared by Suzanne and Robert Fletcher, took forward the concept in Canada where it found its way into the medical programme at McMaster's. Lead by a keen young clinician, David Sackett, he along with colleagues introduced the term 'critical appraisal' as a way for clinicians to read the medical literature. ${ }^{3}$ Concepts further refined by Gordon Guyatt and colleagues led to the EBM concept and the seminal User's Guide to the Medical Literature JAMA series. ${ }^{4}$ On the back of this came the CMAJ's Tips for Teachers and Learners of Evidence-Based Medicine. ${ }^{5}$ In
2005, teachers and developers of Evidence-Based Health Care (EBHC) sought to define evidencebased practice and the minimum standard educational requirements with the Sicily statement. ${ }^{6}$

Teaching EBM skills begins at undergraduate and carries on into postgraduate education, and is taught in many medical, nursing and health sciences schools, however, considerable variation in methods, content and evaluations exists. ${ }^{7}$

\section{The evidence for teaching EBM and EBHC}

Initial enthusiasm for EBM led to innovative teaching strategies-not least the "Evidence Cart.' ${ }^{8}$ Systematic review evidence informed us that standalone teaching improves only knowledge compared with clinically integrated teaching which improves knowledge, skills, attitudes and behaviour. ${ }^{9}$ The evidence cart was the first attempt at this. An overview, of 16 published systematic reviews, assessing the effect of teaching EBHC interventions concluded strategies to enhance competencies needed to focus on implementing multifaceted clinically integrated approaches with assessment. ${ }^{10}$ Conclusions, though, were limited by the poor quality reviews and studies. A more recent review, including 85 controlled trials of evidence-based practice interventions, found that some aspects of evidence-based practice (EBP) such as critical appraisal were focused on more, and there was a lack of highquality instruments to measure outcomes. ${ }^{11}$ A further mapping review of undergraduate EBM teaching in various health disciplines found a focus on teaching critical appraisal and integrating appraised evidence but a lack of evaluation. ${ }^{12}$ Educational packages and instruments which address all EBP steps are, therefore, still much needed.

\section{Call for submissions}

Today, BMJ Evidence-Based Medicine launches a call for submissions for a themed collection (box 1). The need for robust interventions and evaluations of teaching all the five steps of EBM is clear. It was pleasing to see examples at this year's EBM Live conference ${ }^{13}$-we welcome more.

Technological advancements have changed the landscape in which educators can deliver teaching and learning. The field of EBHC can and should maximise this opportunity. Indeed, a number of initiatives are beginning to do so. These include tools to help teachers in the understanding of bias and its impact in health research, ${ }^{14}$ evaluated resources for teachers of EBHC, ${ }^{15}$ as well as innovative online courses for distance learning (being assessed in randomised trials (personal correspondence)). ${ }^{16}$ These are some examples known to us. We want to share others. 
Box 1 Call for submissions to the BMJ EvidenceBased Medicine themed collection on teaching and education in evidence-based healthcare

Aims of the collection

- To better understand the current health research and evidence ecosystem.

- To examine how the current ecosystem affects teaching, education and learning in EBHC.

- To explore contemporary issues with teaching and learning in EBHC, including technological advancements and information needs.

- To share examples of innovative and effective teaching and education strategies in EBHC.

\section{What are we looking for?}

- Submissions for the themed collection are open across all article formats for the BMJ EvidenceBased Medicine. We seek original data, qualitative and quantitative analysis, evidence syntheses, as well as examples of individuals, groups or organisations applying creative and innovative methods of teaching about EBHC.

- We are particularly interested in submissions about teaching the final steps of EBM, in particular, shared decision-making and communication of evidence as well as self-assessment.

- We welcome exploration of new ideas around what, how, why and when we should be teaching and educating in EBHC, including beyond undergraduate and postgraduate contexts (eg, school-aged populations).

- We welcome submissions about research methods and educational pedagogy with application to medical education settings and in relation to the teaching, assessment and evaluation of EBHC.

Submissions are welcome from now, with a final deadline of 20 March 2020.

Normal publication processes for each journal will apply. For feedback on ideas before submission please contact (David Nunan, guest editor).

We intend to launch the full collection at EBM Live in July 2020 (www.ebmlive.org). We look forward to receiving your work.

When the concept of EBM was first introduced, it was done so in a different information landscape. To some extent, EBM has become a victim of its own success-with an insurmountable amount of published 'evidence'. New, more complex, methods of synthesising the best available evidence adds to the increasing knowledge needs. ${ }^{17}$ How should these new methods be taught, and applied in clinical practice?

There is a growing view that expecting health professionals to appraise primary and secondary research is unrealistic, with the emphasis shifting to finding and appraising preappraised resources for their trustworthiness and determining the certainty of the data they present. An intriguing discussion, particularly if we consider the possible implications when trust is lost. In all of this remains the patient: how should communication, shared decision-making and myth busting be taught to convey evidence for better decisions? This is an evidence gap we would like to bridge.
Twitter David Nunan@dnunan79 and Carl Heneghan @ carlheneghan

Contributors DN drafted the initial version of the editorial. All authors agreed on the final version.

Funding The authors have not declared a specific grant for this research from any funding agency in the public, commercial or not-for-profit sectors.

Competing interests The idea for this collection of content was suggested by $\mathrm{CH}$ and adapted in collaboration with the listed authors. DN has received funding for expenses and fees for his media work, and he holds grant funding from the NIHR, the NIHR School of Primary Care Research and the Royal College of General Practitioners. DN is Director of the Postgraduate Certificate in Teaching Evidence-Based Healthcare. CH has received expenses and fees for his media work, and he holds grant funding from the NIHR, the NIHR School of Primary Care Research and The NIHR Oxford BRC. CH is Editor in Chief of BMJ Evidence-Based Medicine, an NHS urgent care GP and Director of CEBM, which jointly runs the EBM Live Conference with the BMJ and the Overdiagnosis Conference with international partners based on a non-profit model. RJ holds grants from the New Zealand Health Research Council, Heart Foundation and Ministry of Business, Innovation and Employment. He is a professor of epidemiology at the University of Auckland and has contributed to annual University of Oxford Teaching EBM courses for over 20 years.

Patient consent for publication Not required.

Provenance and peer review Commissioned; internally peer reviewed.

\section{ORCID iDs}

David Nunan http://orcid.org/0000-0003-4597-1276

Carl Heneghan http://orcid.org/0000-0002-1009-1992

\section{References}

1 Glasziou P, Burls A, Gilbert R. Evidence based medicine and the medical curriculum. BMJ 2008;337:a1253.

2 Evidence-Based Medicine Working Group. A new approach to teaching the practice of evidence medicine. Evidence-Based Medicine, 2019.

3 Sur R, Dahm P. History of evidence-based medicine. Indian J Urol 2011;27:487-9.

4 Users' guides to the medical literature: a manual for evidence-based clinical practice, 3rd ED. Available: https://jamaevidence.mhmedical.com/ book.aspx?bookID=847\&TopLevelContentDisplayName=Books [Accessed 25 October 2019]

5 Wyer PCet al. Tips for learning and teaching evidence-based medicine: introduction to the series. Can Med Assoc J 2004;171:347-8.

6 Dawes M, Summerskill W, Glasziou P, et al. Sicily statement on evidencebased practice. BMC Med Educ 2005;5:1.

7 Meats E, Heneghan C, Crilly M, et al. Evidence-Based medicine teaching in UK medical schools. Med Teach 2009;31:332-7.

8 Sackett DL, Straus SE. Finding and applying evidence during clinical rounds: the "evidence cart". JAMA 1998;280:1336-8.

9 Coomarasamy A, Khan KS. What is the evidence that postgraduate teaching in evidence based medicine changes anything? A systematic review. BMJ 2004;329.

10 Young T, Rohwer A, Volmink J, et al. What are the effects of teaching evidence-based health care (EBHC)? overview of systematic reviews. PLoS One;9:e86706.

11 Albarqouni L, Hoffmann T, Strauss S, et al. Core competencies in evidence-based practice for health professionals: consensus statement based on a systematic review and Delphi survey. JAMA Netw Open 2018;1:e180281. 
12 Larsen CM, Terkelsen AS, Carlsen A-MF, et al. Methods for teaching evidence-based practice: a scoping review. BMC Med Educ 2019;19:259.

13 Kumaravel B, Ratnakumar S, Jenkins H, et al. A multifaceted, clinically integrated evidence based medicine curriculum improves medical students' competency as measured by the Fresno test. BMJ Evidence-Based Medicine 2019;24:A14.

14 Catalog of bias. Available: https://catalogofbias.org/ [Accessed 25 Oct 2019].
15 Teachers of evidence-based health care. Available: https://teachingebhc. org/ [Accessed 25 Oct 2019].

16 Youtube. Introducing a short course in evidence-based medicine: the primer. Available: https://www.youtube.com/watch?v=jcGkG30r3aQ

17 Tricco AC, Soobiah C, Antony J, et al. A scoping review identifies multiple emerging knowledge synthesis methods, but few studies operationalize the method. J Clin Epidemiol 2016;73:19-28. 


\section{Correction: What next for education in evidence-based healthcare? A call for submissions}

Nunan D, Jackson R, Heneghan C. What next for education in evidence-based healthcare? A call for submissions. BMJ Evidence-Based Medicine 2020;25:1-2. doi: 10.1136/bmjebm-2019-111301

In this paper, the deadline for submission has been extended until July 10th, 2020.

( Author(s) (or their employer(s)) 2020. No commercial re-use. See rights and permissions. Published by BMJ.

BMJ Evidence-Based Medicine 2020;25:e5. doi:10.1136/bmjebm-2019-111301corr1

(A) Check for updates 